\title{
Effect of lentivirus-mediated shRNA inactivation of HK1, HK2, and HK3 genes in colorectal cancer and melanoma cells
}

Anna V. Kudryavtseva ${ }^{1,2^{*}}$, Maria S. Fedorova ${ }^{1}$, Alex Zhavoronkov ${ }^{3}$, Alexey A. Moskalev ${ }^{1,4}$, Alexander S. Zasedatelev ${ }^{1,5}$, Alexey A. Dmitriev", Asiya F. Sadritdinova ${ }^{1,2}$, Irina Y. Karpova', Kirill M. Nyushko², Dmitry V. Kalinin ${ }^{6}$, Nadezhda N. Volchenko², Nataliya V. Melnikova', Kseniya M. Klimina', Dmitry V. Sidorov², Anatoly Y. Popov', Tatiana V. Nasedkina ${ }^{1,5}$, Andrey D. Kaprin², Boris Y. Alekseev², George S. Krasnov ${ }^{1}$ and Anastasiya V. Snezhkina ${ }^{1}$

From The International Conference on Bioinformatics of Genome Regulation and StructurelSystems Biology (BGRSISB-2016) Novosibirsk, Russia. 29 August-2 September 2016

\begin{abstract}
Background: The switch from oxidative phosphorylation to glycolysis in proliferating cancer cells, even under aerobic conditions, has been shown first in 1926 by Otto Warburg. Today this phenomenon is known as the "Warburg effect" and recognized as

a hallmark of cancer. The metabolic shift to glycolysis is associated with the alterations in signaling pathways involved in energy metabolism, including glucose uptake and fermentation, and regulation of mitochondrial functions. Hexokinases (HKs), which catalyze the first step of glycolysis, have been identified to play a role in tumorigenesis of human colorectal cancer (CRC) and melanoma. However, the mechanism of action of HKs in the promotion of tumor growth remains unclear.
\end{abstract}

Results: The purpose of the present study was to investigate the effect of silencing of hexokinase genes (HK1, HK2, and HK3) in colorectal cancer (HT-29, SW 480, HCT-15, RKO, and HCT 116) and melanoma (MDA-MB-435S and SK-MEL-28) cell lines using short hairpin RNA (shRNA) lentiviral vectors. shRNA lentiviral plasmid vectors pLSLP-HK1, pLSLP-HK2, and pLSLP-HK3 were constructed and then transfected separately or co-transfected into the cells. HK2 inactivation was associated with increased expression of HK1 in colorectal cancer cell lines pointing to the compensation effect. Simultaneous attenuation of HK1 and HK2 levels led to decreased cell viability. Co-transfection with shRNA vectors against $H K 1, H K 2$, and $H K 3$ mRNAs resulted in a rapid cell death via apoptosis.

Conclusions: We have demonstrated that simultaneous inactivation of HK1 and HK2 was sufficient to decrease proliferation and viability of melanoma and colorectal cancer cells. Our results suggest that HK1 and HK2 could be the key therapeutic targets for reducing aerobic glycolysis in examined cancers.

Keywords: Warburg effect, Hexokinases, shRNA, Glycolysis, Melanoma, Colorectal cancer

\footnotetext{
* Correspondence: rhizamoeba@mail.ru

${ }^{1}$ Engelhardt Institute of Molecular Biology, Russian Academy of Sciences,

Moscow, Russia

${ }^{2}$ National Medical Research Radiological Center, Ministry of Health of the

Russian Federation, Moscow, Russia

Full list of author information is available at the end of the article
} 


\section{Background}

In the beginning of the 20th century, Otto Warburg with his colleagues observed that cancer cells used glycolysis and produced lactate instead of mitochondrial respiration, even in the presence of oxygen and could die through hypoxia if glucose is lacking. Nowadays, this phenomenon is known as "Warburg effect" [1, 2]. Many cancers are characterized by increased aerobic glycolysis [2-5]. In the hypoxic microenvironment, it confers several advantages to cancer cells. Firstly, high rate of glycolysis provides sufficient ATP for tumor cells under reduced mitochondrial function [6-8]. Secondly, glycolysis is a source of the metabolic intermediates (e.g., ribose sugars, glycerol, citrate, nonessential amino acids and $\mathrm{NADPH}$ ) that are needed for biosynthetic pathways [9]. Finally, tumor cells produce large amount of lactic acid during glucose metabolism that promotes activation of metalloproteinases and matrix remodeling enzymes involved in invasion and metastasis [10]. So, the Warburg effect benefits for the adaptation, proliferation and survival of cancer cells.

Hexokinases (HKs) catalyze the crucial step in glycolysis in which the glucose is phosphorylated to produce glucose-6-phosphate [11]. Four isozymes of hexokinase were found in mammalian tissues: HK1, HK2, HK3 and HK4 (glucokinase) [12, 13]. The alterations in the expression of hexokinase isoenzymes play a role in the tumor initiation and promotion. It has been observed that the tumor cells adapted metabolically primarily by increasing the expression of HK2 [14, 15]. The elevated expression of HK1 was also detected in several tumors, but at lower extent compared to the HK2 isozyme [16-18]. The increased expression of HK3 was shown in colorectal, lung, gastrointestinal, and breast cancers [11, 19]. For liver tumors, a shift in expression from HK4 to HK1 and HK2 was observed [11, 20]. In has been shown that in tumor cells cytosolic HK1 and HK2 were tightly associated to the voltage-dependent anion channel (VDAC) in the mitochondrial membrane $[15,21]$. Its interaction has dual function: (1) prevention of mitochondrial outer membrane permeabilization and evasion of subsequent apoptosis, and (2) inhibition of VDAC to facilitate shuttling of ATP from mitochondria into the cytosol $[22,23]$. This is also the evidence that HK1 and HK2 are responsible for the accelerated glucose flux in tumor cells. Thus, altered expression of HKs in tumors is a potential target for cancer therapy.

Colorectal cancer (CRC) and malignant melanoma $(\mathrm{MM})$ are very aggressive and deadly cancers with high metastatic rates [24]. The risk of both tumors increases with age [25-28]. Most cases of CRC and melanoma are sporadic and driven by genetic and epigenetic alterations involved in the activation of oncogenes and inactivation of tumor suppressor genes [29-32]. However, around $10-30 \%$ of all CRC and 3-15\% of MM cases have a hereditary nature [33-35]. CRC and melanoma usually develop without any symptoms for a long time. Many cases of CRC and MM are diagnosed in advanced stages [36-38]. At present, there are few treatment options for patients with CRC or melanoma, but the classical therapies have limited efficiency whereas global incidence of the diseases is increasing very fast $[39,40]$. It is important to uncover the molecular mechanisms of the development and progression of CRC and MM for better prevention, diagnosis, and clinical management.

In the present study, to understand the mechanism of aerobic glycolysis in CRC and MM, we investigated the effect of silencing of hexokinase genes in colorectal cancer and melanoma cells using short hairpin RNA (shRNA) lentiviral vectors. Our results suggest HK1 and HK2 as key enzymes for glucose metabolism associated with survival of tumor cells. We determined the significance of HK gene expression in colorectal cancer and melanoma cells and proposed a promising strategy for therapy of the diseases.

\section{Methods}

\section{Cell cultures}

Colorectal adenocarcinoma (HT-29, SW 480, HCT-15, RKO, and HCT 116) and melanoma (MDA-MB-435S and SK-MEL-28) cells were obtained from N.N. Blokhin Russian Cancer Research Center (Moscow, Russia). They were maintained in Dulbecco's modified Eagle's medium (DMEM) (Thermo Fisher Scientific, USA) supplemented with 10\% FBS (Harlan Sera-Lab, UK), penicillin $(100 \mathrm{U} / \mathrm{ml})$, and streptomycin $(100 \mu \mathrm{g} / \mathrm{ml})$ (Thermo Fisher Scientific, USA). The cells were cultured at $37{ }^{\circ} \mathrm{C}$ in a $5 \% \mathrm{CO}_{2}$ atmosphere and passaged every 2-3 days by dissociation with trypsin (Thermo Fisher Scientific, USA).

\section{Constructs and production of lentivirus}

Nine hairpin RNAs were constructed to specifically target $H K 1, H K 2$, and $H K 3$ mRNA (3 interference sequences per each gene) by shRNA design tools (http://rnaidesig ner.thermofisher.com/rnaiexpress/). Using BLAST (http:// blast.ncbi.nlm.nih.gov/Blast.cgi) we have seen that the designed shRNAs targeted only the selected genes. ShRNAs were synthesized by Evrogen (Russia) (Table 1). Their sequences were annealed and cloned between EcoRI and BamHI restriction sites in the pLSLP lentiviral vector and checked by Sanger sequencing on ABI Prism 3100 Genetic Analyzer (Thermo Fisher Scientific, USA).

\section{Cell transfection}

The constructed vectors were transfected into the cells using Lipofectamin 2000 (Thermo Fisher Scientific, 
Table 1 shRNA sequences

\begin{tabular}{|c|c|}
\hline Primer name & shRNA sequences \\
\hline HK1_sh1_t & gatccgGGAACTGAGGCACATTGATCTCACGTGAGATCAATGTGCCTCAGTTCCtttttg \\
\hline HK1_sh1_b & aattcaaaaaGGAACTGAGGCACATTGATCTCACGTGAGATCAATGTGCCTCAGTTCCcg \\
\hline HK1_sh2_t & gatccgGCCTTTGGAGACGATGGATCACACGTGTGATCCATCGTCTCCAAAGGCtttttg \\
\hline HK1_sh2_b & aattcaaaaaGCCTTGGAGACGATGGATCACACGTGTGATCCATCGTCTCCAAAGGCcg \\
\hline HK1_sh3_t & gatccgGGAAGCAGACGCACAACAATGCACGTGCATTGTTGTGCGTCTGCTTCCtttttg \\
\hline HK1_sh3_b & aattcaaaaaGGAAGCAGACGCACAACAATGCACGTGCATTGTTGTGCGTCTGCTTCCcg \\
\hline HK2_sh1_t & gatccgGGGTGAAAGTAACGGACAATGCACGTGCATTGTCCGTTACTTTCACCCtttttg \\
\hline HK2_sh1_b & aattcaaaaaGGGTGAAAGTAACGGACAATGCACGTGCATTGTCCGTTACTTTCACCCcg \\
\hline HK2_sh2_t & gatccgGCAGAAGGTTGACCAGTATCTCACGTGAGATACTGGTCAACCTTCTGCtttttg \\
\hline HK2_sh2_b & aattcaaaaaGCAGAAGGTTGACCAGTATCTCACGTGAGATACTGGTCAACCTTCTGCcg \\
\hline HK2_sh3_t & gatccgGGGACTITGATATCGACATTGCACGTGCAATGTCGATATCAAAGTCCCtttttg \\
\hline HK2_sh3_b & aattcaaaaaGGGACTITGATATCGACATTGCACGTGCAATGTCGATATCAAAGTCCCcg \\
\hline HK3_sh1_t & gatccgGGGTGACTCTAACTGGCATTGCACGTGCAATGCCAGTTAGAGTCACCCtttttg \\
\hline HK3_sh1_b & aattcaaaaaGGGTGACTCTAACTGGCATTGCACGTGCAATGCCAGTTAGAGTCACCCcg \\
\hline HK3_sh2_t & gatccgGCTGAATGTGGTTGCCATTGTCACGTGACAATGGCAACCACATTCAGCtttttg \\
\hline HK3_sh2_b & aattcaaaaaGCTGAATGTGGTTGCCATTGTCACGTGACAATGGCAACCACATTCAGCcg \\
\hline HK3_sh3_t & gatccgGGCTTCGGATGTTGAGCTTGTCACGTGACAAGCTCAACATCCGAAGCCtttttg \\
\hline HK3_sh3_b & aattcaaaaaGGCTTCGGATGTTGAGCTTGTCACGTGACAAGCTCAACATCCGAAGCCcg \\
\hline
\end{tabular}

USA) according to manufacturer's instructions. The transfected cells were then selected by puromycin $(10 \mathrm{mg} / \mathrm{ml})$ for 5 days. The puromycin-resistant colonies were then picked and expanded. HK expression levels in selected clones were determined by quantitative PCR (qPCR) and Western blot analysis.

\section{RNA extraction and CDNA synthesis}

The total RNA was isolated using RNeasy Mini kit (Qiagen, Germany) according to manufacturer's protocol. RNA quality was monitored with absorbance spectra (NanoDrop Technologies Inc., USA) and the RNA integrity number (RIN; Agilent Technologies, USA). The RNA samples were treated with DNase I (Thermo Fisher Scientific, USA). cDNA was synthesized using M-MLV Reverse Transcriptase (Thermo Fisher Scientific, USA) and random primers.

\section{Quantification of gene expression by qPCR}

Gene expression was analyzed using qPCR with TaqMan Gene Expression Assays (Thermo Fisher Scientific, USA) and TaqMan Universal Master Mix (Thermo Fisher Scientific, USA) according to the manufacturer's recommendations. The reactions were performed using $A B$ 7500 Real-Time PCR System (Thermo Fisher Scientific, USA) with RQ (Relative Quantitation) software (Thermo Fisher Scientific, USA). PCR program was as follow: $10 \mathrm{~min}$ at $95{ }^{\circ} \mathrm{C}$, then 50 two-step cycles $15 \mathrm{~s}$ at $95{ }^{\circ} \mathrm{C}$ and $60 \mathrm{~s}$ at $60{ }^{\circ} \mathrm{C}$. Total reaction volume was $20 \mu \mathrm{l}$ in triplicate. PCR products were analyzed in $2 \%$ agarose gels and nucleotide sequences of the amplicons were verified by Sanger sequencing on ABI Prism 3100 Genetic Analyzer (Thermo Fisher Scientific, USA).

\section{Western blot analysis}

Proteins were extracted using radioimmunoprecipitation assay lysis buffer (RIPA buffer). The concentration and purity of proteins were analyzed on Agilent Bioanalyzer 2100 (Agilent Technologies, USA). Subsequently, proteins $(20 \mu \mathrm{g})$ were separated by electrophoresis on a SDS-PAGE gel and transferred onto a polyvinylidene fluoride membrane. The membrane was blocked in 3\% BSA in Tris-buffered saline in $0.1 \%$ Tween 20 (TBST) at room temperature for $1 \mathrm{~h}$ and then incubated overnight in the primary antibody solution (MA5-14789, MA5-14849, and PA5-29304) (Thermo Fisher Scientific, USA) at $4{ }^{\circ} \mathrm{C}$. Next, the samples were washed three times with TBST, and the membrane was incubated with secondary antibody solution (A-11008) (Thermo Fisher Scientific, USA) for $1 \mathrm{~h}$ at room temperature. After incubation, the samples were washed five times and the bands were detected using Pierce ECL Western Blotting Substrate (Thermo Fisher Scientific, USA) on a Gel Doc XR+ System (Bio-Rad, USA) and analyzed with Image Lab Software (Bio-Rad, USA). $\beta$-actin was used for normalization. 


\section{Cell proliferation and viability assay}

Cell proliferation and viability were measured by MTT assay (Promega, USA) according to the manufacturer's instructions. The transfected cells were incubated with tetrazolium dye solution. The formazan absorbance was then recorded at $570 \mathrm{~nm}$ using a multi-mode microplate reader CHAMELEON V (Hidex, Turkey).

\section{Analysis of DNA fragmentation}

The apoptosis in transfected cells was determined using Apoptotic DNA-Ladder Kit (Roche, Switzerland) according to the manufacturer's protocol. The DNA samples were electrophoresed on a $2 \%$ agarose gels containing $1 \mu \mathrm{L} / 10 \mathrm{~mL}$ GelGreen nucleic acid gel stain (Biotium, USA). The gels were examined by an ultraviolet gel documentation system Gel Doc XR+ System (Bio-Rad, USA). Apoptosis was visualized as a ladder pattern of 180-200 bp due to DNA cleavage by the activation of a nuclear endonuclease.

\section{Statistical analysis}

We applied the nonparametric Wilcoxon/Mann-Whitney U-test to measure statistical significance between the two groups. We used Kruskal-Wallis test for multiple comparisons. Data were considered significant at $P<0.05$. The statistical procedures were performed with a BioStat 2009 professional software (AnalystSoft Inc., USA).

\section{Results}

Expression of HK mRNA in cell lines is silenced by shRNA In order to silence the expression of HK mRNA in colorectal cancer and melanoma cells, the cell lines were transfected with HK1, HK2, and HK3 shRNA (three shRNAs per each gene: $\operatorname{sh} \# 1, \operatorname{sh} \# 2$, and $\operatorname{sh} \# 3)$. qPCR and Western blot analysis showed that HK1 sh\#1, HK2 sh\#3, and HK3 sh\#3 significantly repressed the expression of target genes in cells to be tested (Fig. 1). Therefore, these shRNAs were used in the following experiments.

HK mRNA expression levels in cells transfected separately with three lentiviral vectors PLSLP-HK1, pLSLP-HK2, and pLSLP-HK3

Expression levels of HKs in cell lines that were separately transfected with three lentiviral vectors against $H K 1, H K 2$, and $H K 3$ genes were determined using $\mathrm{qPCR}$ and Western blot analysis. The expression levels of HK1 and HK2 were not significantly changed in both colorectal cancer and melanoma cells with HK3 knockdown. We observed increased expression of HK1 in colorectal cancer cells transfected by vector pLSLP-HK2, but not

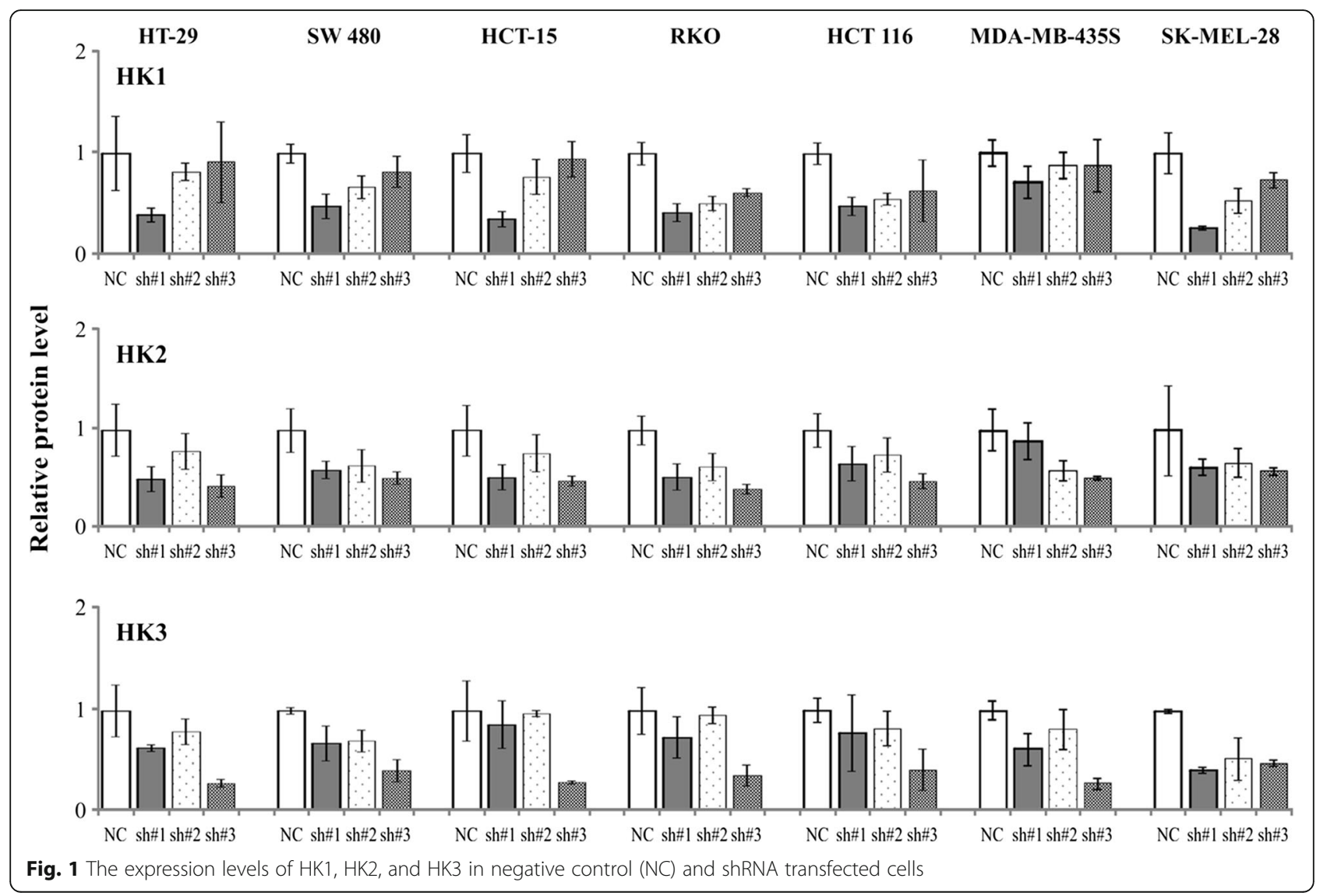


in melanoma ones; the mRNA and protein levels of HK3 were not altered in all cases. Expression differences of HK2 and HK3 between pLSLP-HK1 transfected cells and control were not significant. Generally, we showed the absence of compensatory expression between the $H K$ genes in melanoma cells. These data suggest that the increased expression of HK1 gene may play a role in maintaining of high rates of glycolysis in colorectal cancer cells when HK2 is suppressed (Fig. 2).

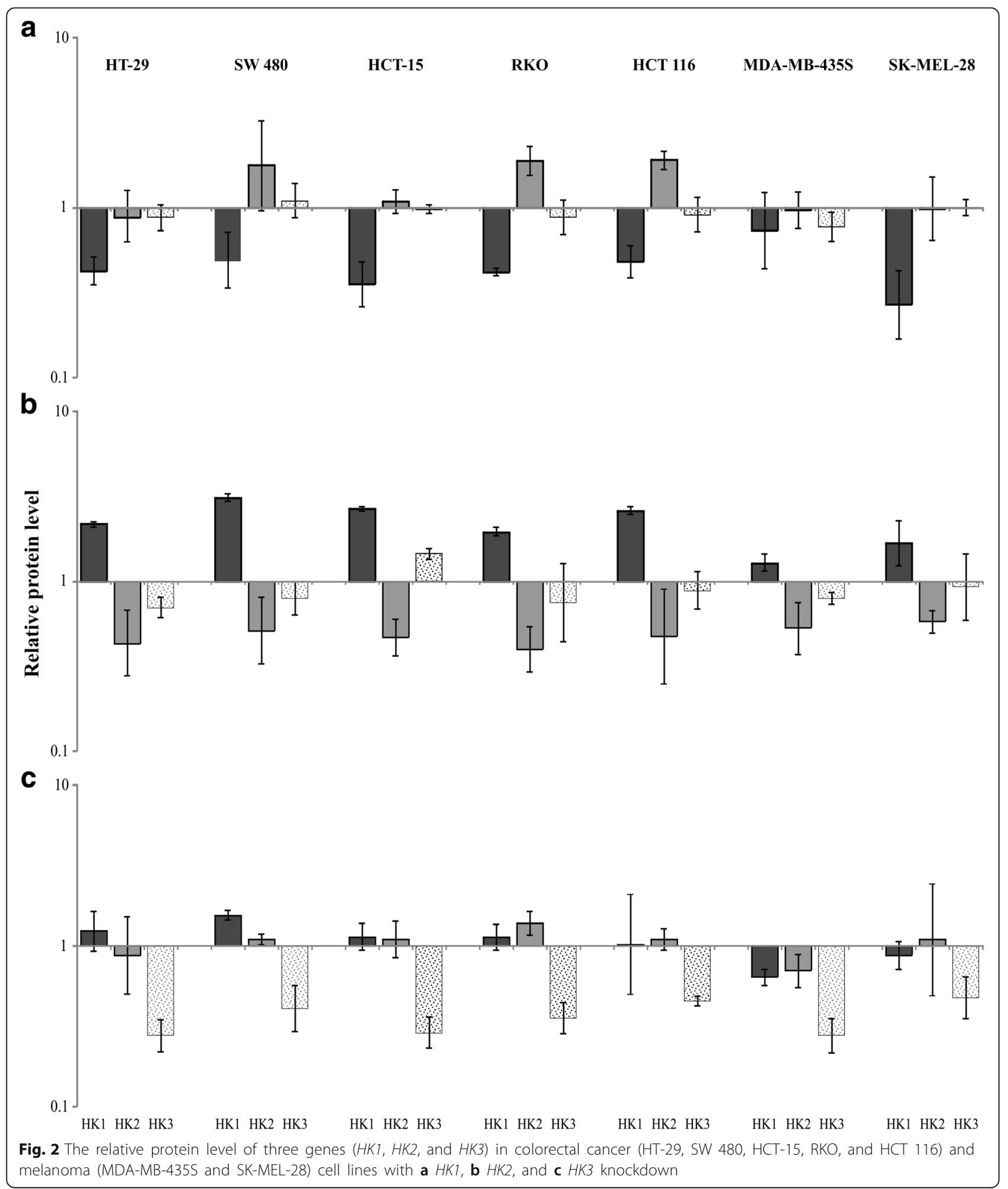


Simultaneous down-regulation of HK expression induces apoptosis and inhibits tumor growth in vitro

As shown in Fig. 3, cells transfected by different combinations of lentiviral vectors against hexokinases showed decreased viability and time-dependent inhibition of proliferation. This effect is stronger in cells with simultaneous knockdown of $H K 1, H K 2$ and $H K 3$ genes. Both colorectal cancer and melanoma cells are more sensitive to $H K 1$ and $H K 2$ deficiency. Viability of the cells transfected by lentiviral vectors pLSLP-HK1 and pLSLP-HK2 was lower than cells transfected by other double combination of ones (pLSLP-HK1 and pLSLP-HK3 or pLSLP-HK2 and pLSLP-HK3).

Formation of fragmented DNA is one of the typical apoptotic features. We performed DNA fragmentation assay to reveal whether apoptosis plays an important role in cell death. Multiple DNA fragments were detected in the cells co-transfected by pLSLP-HK1, pLSLP-HK2, and pLSLPHK3. These data suggest that simultaneous downregulation of $H K 1, H K 2$, and $H K 3$ gene expression could induce apoptosis in colorectal cancer and melanoma cells.

\section{Discussion}

Activation of aerobic glycolysis occurs in almost all cancer cells. The process has a very strong regulatory system, because in addition to ATP production glycolysis supplies actively proliferating tumor cells with building blocks [41, 42]. Hexokinases, as the key glycolytic enzymes, may be regulated more extensively in glycolysis process [43]. We have previously shown deregulation in the expression of $H K$ genes in colorectal cancer [19]. In this study, using shRNA-based gene knockdown we have checked the compensatory expression between the HK genes, and analyzed the viability of colorectal cancer and melanoma cells when various hexokinase isoenzymes were inactive. We have shown that shRNA-mediated attenuation of $H K 1$ and $H K 2$ together led to decreased cell viability. $H K 2$ gene inactivation was associated with increased expression of HK1 in colorectal cancer cells. The compensatory expression between the $H K$ genes was not detected in melanoma cells. Co-transfection by shRNA vectors against mRNA of $H K 1, H K 2$, and $H K 3$ genes resulted in a rapid cell death by apoptosis.

HK1 and HK2 play an important role in glycolysis [41]. They are associated with the outer mitochondrial membrane via VDAC and implicated in cell survival [13, 44-49]. HK2 expression is limited in most normal tissues, but frequently up-regulated in cancer [48, 50-52]. It is known that $H K 2$ is a target for several oncogenic transcription factors (HIF-1, Myc, and p53) [42], and is involved in Akt signaling pathway [43]. The overexpression of HK2 provides tumor cells with a growth advantage due to increased glycolytic activity, prevents from apoptosis, and increases their possibility for metastasis [53]. High HK2 expression in lung, ovarian, pancreatic, breast cancers and hepatocellular carcinoma was shown to be associated with poor patient prognosis [50, 54-58].
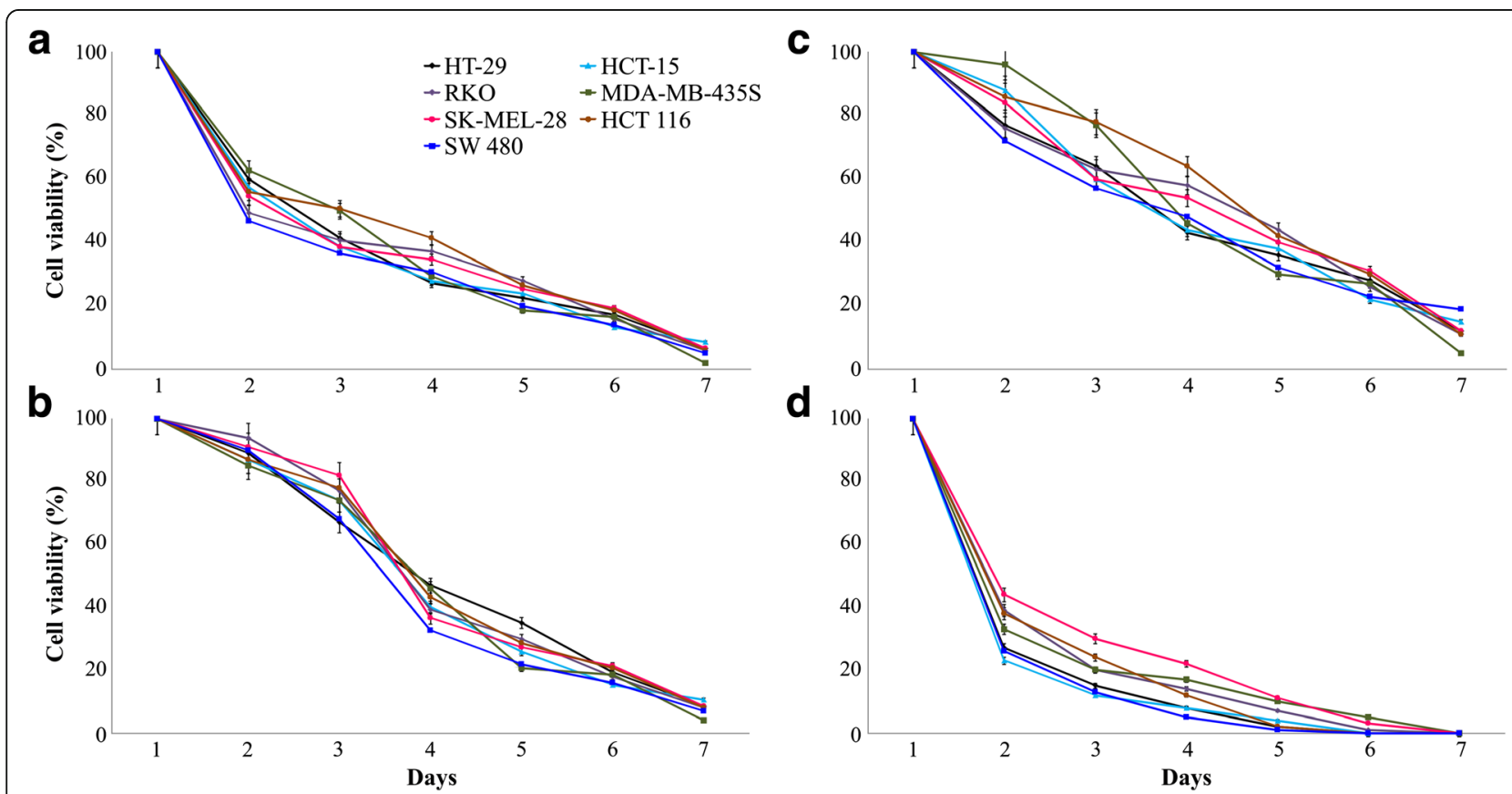

Fig. 3 Inhibitory effect of HK1, HK2 and HK3 knockdown on cell growth and proliferation. Viability of colorectal cancer HT-29 (black), SW 480 (blue), HCT-15 (light blue), RKO (purple), HCT 116 (brown) and melanoma MDA-MB-435S (green), SK-MEL-28 (red) cell lines transfected by lentiviral vectors pLSLP-HK1 plus pLSLP-HK2 (a), pLSLP-HK1 plus pLSLP-HK3 (b), pLSLP-HK2 plus pLSLP-HK3 (c), and pLSLP-HK1, pLSLP-HK2 plus pLSLP-HK3 (d) 
Bryson and colleagues have demonstrated that primary increase in HK1 activity reduced susceptibility of renal epithelial cells to oxidant-induced cell death [59]. The series of studies have shown up-regulation of HK1 in several tumors, including colorectal, gastric, and thyroid cancer, and supposed it as an unfavorable prognostic factor [60-62]. We observed increased expression of HK1 in colorectal cancer cells with $H K 2$ gene silencing, but not in melanoma cells. In cells with $H K 1$ or $H K 3$ knockdown, change in HK1 expression was insignificant. Simultaneous down-regulation of $H K 1$ and $H K 2$ genes led to reduction of cell proliferation and viability compared to double knockdown of $H K 1 / H K 3$ or $H K 2 / H K 3$ genes. Noteworthy, Patra et al. have demonstrated that oncogenic HK2 expression and activity cannot be compensated by HK1 in mouse embryonic fibroblasts [54]. Our results confirm that HK1 and HK2 are involved in tumor growth maintenance. However, we can assume that despite the increase in the expression of HK1 in colorectal cancer it may be insufficient to maintain high level of aerobic glycolysis. Overexpression of HK1 in tumors seems to be the mechanism for the protection of cancer cells against oxidative stress and apoptosis, as well.

HK3 activity is regulated by HIF-dependent pathway and glucose level. Overexpression of HK3 results in increased cellular ATP and reduced ROS production, and promotes the expression of genes involved in mitochondrial biogenesis. These processes can mediate the cytoprotective effect of HK3 [43]. In the study, the expression levels of HK1 and HK2 were not significantly changed in cells with HK3 knockdown that indicate its lower importance in the regulation of glycolysis rate.

\section{Conclusion}

We have demonstrated that simultaneous HK1 and HK2 deficiency results in decreased cell survival whereas inactivation of HK1, HK2, and HK3 led to rapid cell death via apoptosis. Inactivation of HK2 was followed with up-regulation of HK1 expression in colorectal cancer, but not in melanoma cells. Taken together, our results suggest $H K 1$ and $H K 2$ genes as the potential molecular targets for colorectal cancer and melanoma therapy.

\section{Acknowledgements}

Authors thank N.N. Blokhin Russian Cancer Research Center, National Medical Research Center of Radiology, A.V. Vishnevsky Institute of Surgery, and State Hospital №57 for supplying and characterization of cell cultures; Vavilov Institute of General Genetics, Insilico Medicine, Inc., and Moscow Institute of Physics and Technology for the assistance in bioinformatics analysis.

\section{Declarations}

This article has been published as part of BMC Genetics Vol 17 Suppl 3, 2016: Selected articles from BGRSISB-2016: genetics. The full contents of the supplement are available online at https://bmcgenet.biomedcentral.com/ articles/supplements/volume-17-supplement-3.

\section{Funding}

Part of this work devoted to melanoma research was supported by the Russian Science Foundation grant no. 14-35-00107. Part of this work devoted to colorectal cancer research was supported by the Russian Science Foundation grant no. 14-15-01083. Publication of this article has been funded by the Russian Science Foundation grants no. 14-15-01083 and 14-35-00107. Part of this work (isolation of RNA, CDNA synthesis, analysis of DNA fragmentation, and quantitative $P(R)$ was performed using the equipment of EIMB RAS "Genome" center (http://www.eimb.ru/rus/ckp/

ccu_genome_c.php).

\section{Authors' contributions}

AVK and AVS were responsible for the study design. GSK, AAD, and NVM performed data analysis. KMK, AFS, and IYK performed construction of shRNA lentiviral vectors and cell transfection. ASZ and TVN assisted in cell culture collection. MSF and AVK wrote the manuscript. AAM, ADK, and BYA collaborated in the discussion and in writing the manuscript. KMN, DVK, NNV, DVS, AZ, and AYP participated in the interpretation of the results and review of the paper. All authors read and approved the final manuscript.

\section{Competing interests}

The authors declare that they have no competing interests.

\section{Consent for publication}

Not applicable.

\section{Ethics approval and consent to participate} Not applicable.

\section{Author details}

${ }^{1}$ Engelhardt Institute of Molecular Biology, Russian Academy of Sciences, Moscow, Russia. ${ }^{2}$ National Medical Research Radiological Center, Ministry of Health of the Russian Federation, Moscow, Russia. ${ }^{3}$ Insilico Medicine, Inc., Emerging Technology Centers, Johns Hopkins University Eastern Campus, Baltimore, Maryland, USA. ${ }^{4}$ Moscow Institute of Physics and Technology, Dolgoprudny, Russia. ${ }^{5}$ N.N. Blokhin Russian Cancer Research Center, Moscow, Russia. ${ }^{6}$ A.V. Vishnevsky Institute of Surgery, Moscow, Russia. "Vavilov Institute of General Genetics, Russian Academy of Sciences, Moscow, Russia. ${ }^{8}$ State Hospital №57, Moscow, Russia.

Published: 22 December 2016

\section{References}

1. Warburg O, Wind F, Negelein E. The Metabolism of Tumors in the Body. J Gen Physiol. 1927;8(6):519-30.

2. Vander Heiden MG, Cantley LC, Thompson CB. Understanding the Warburg effect: the metabolic requirements of cell proliferation. Science. 2009; 324(5930):1029-33.

3. Hersey P, Watts RN, Zhang XD, Hackett J. Metabolic approaches to treatment of melanoma. Clin Cancer Res. 2009:15(21):6490-4.

4. Graziano F, Ruzzo A, Giacomini E, Ricciardi T, Aprile G, Loupakis F, Lorenzini $P$, Ongaro E, Zoratto F, Catalano V et al. Glycolysis gene expression analysis and selective metabolic advantage in the clinical progression of colorectal cancer. Pharmacogenomics J. 2016. doi:10.1038/tpj.2016.13.

5. Oparina NY, Snezhkina AV, Sadritdinova AF, Veselovskii VA, Dmitriev AA, Senchenko VN, Mel'nikova NV, Speranskaya AS, Darii MV, Stepanov OA, et al. Differential expression of genes that encode glycolysis enzymes in kidney and lung cancer in humans. Russ J Genet. 2013;49(7):707-16.

6. Warburg O. On the origin of cancer cells. Science. 1956;123(3191):309-14.

7. Hammoudi N, Ahmed KB, Garcia-Prieto C, Huang P. Metabolic alterations in cancer cells and therapeutic implications. Chin J Cancer. 2011;30(8):508-25.

8. Krasnov GS, Dmitriev AA, Snezhkina AV, Kudryavtseva AV. Deregulation of glycolysis in cancer: glyceraldehyde-3-phosphate dehydrogenase as a therapeutic target. Expert Opin Ther Targets. 2013;17(6):681-93. 
9. DeBerardinis RJ, Lum JJ, Hatzivassiliou G, Thompson CB. The biology of cancer: metabolic reprogramming fuels cell growth and proliferation. Cell Metab. 2008;7(1):11-20.

10. Berardi MJ, Fantin VR. Survival of the fittest: metabolic adaptations in cancer. Curr Opin Genet Dev. 2011;21(1):59-66.

11. Smith TA. Mammalian hexokinases and their abnormal expression in cancer. Br J Biomed Sci. 2000;57(2):170-8.

12. Wilson JE. Hexokinases. Rev Physiol Biochem Pharmacol. 1995;126:65-198.

13. Wilson JE. Isozymes of mammalian hexokinase: structure, subcellular localization and metabolic function. J Exp Biol. 2003:206(Pt 12):2049-57.

14. Mathupala SP, Rempel A, Pedersen PL. Aberrant glycolytic metabolism of cancer cells: a remarkable coordination of genetic, transcriptional, posttranslational, and mutational events that lead to a critical role for type II hexokinase. J Bioenerg Biomembr. 1997;29(4):339-43.

15. Krasnov GS, Dmitriev AA, Lakunina VA, Kirpiy AA, Kudryavtseva AV. Targeting VDAC-bound hexokinase II: a promising approach for concomitant anticancer therapy. Expert Opin Ther Targets. 2013;17(10):1221-33.

16. Rempel A, Bannasch P, Mayer D. Differences in expression and intracellular distribution of hexokinase isoenzymes in rat liver cells of different transformation stages. Biochim Biophys Acta. 1994;1219(3):660-8.

17. Verhagen JN, Van der Heijden MC, Rijksen G, Der Kinderen PJ, Van Unnik JA, Staal GE. Determination and characterization of hexokinase in thyroid cancer and benign neoplasms. Cancer. 1985;55(7):1519-24.

18. Pedersen PL, Mathupala S, Rempel A, Geschwind JF, Ko YH. Mitochondrial bound type II hexokinase: a key player in the growth and survival of many cancers and an ideal prospect for therapeutic intervention. Biochim Biophys Acta. 2002;1555(1-3):14-20.

19. Krasnov GS, Dmitriev AA, Sadtritdinova AF, Fedorova MS, Snezhkina AV, Melnikova NV, Poteryakhina AV, Nyushko KM, Belyakov MM, Kaprin AD, et al. Evaluation of Gene Expression of Hexokinases in Colorectal Cancer with the Use of Bioinformatics Methods. Biofizika. 2015;60(6):1050-6.

20. Mayer D, Klimek F, Rempel A, Bannasch P. Hexokinase expression in liver preneoplasia and neoplasia. Biochem Soc Trans. 1997;25(1):122-7.

21. Pedersen PL. Warburg, me and Hexokinase 2: Multiple discoveries of key molecular events underlying one of cancers' most common phenotypes, the "Warburg Effect", i.e., elevated glycolysis in the presence of oxygen. J Bioenerg Biomembr. 2007;39(3):211-22.

22. Robey RB, Hay N. Mitochondrial hexokinases, novel mediators of the antiapoptotic effects of growth factors and Akt. Oncogene. 2006;25(34): 4683-96.

23. Galluzzi L, Kepp O, Tajeddine N, Kroemer G. Disruption of the hexokinaseVDAC complex for tumor therapy. Oncogene. 2008;27(34):4633-5.

24. Weitz J, Koch M, Debus J, Hohler T, Galle PR, Buchler MW. Colorectal cancer. Lancet. 2005:365(9454):153-65.

25. Murphy G, Devesa SS, Cross AJ, Inskip PD, McGlynn KA, Cook MB. Sex disparities in colorectal cancer incidence by anatomic subsite, race and age. Int J Cancer. 2011;128(7):1668-75.

26. Cho E, Rosner BA, Feskanich D, Colditz GA. Risk factors and individual probabilities of melanoma for whites. J Clin Oncol. 2005;23(12): 2669-75.

27. Kudryavtseva AV, Krasnov GS, Dmitriev AA, Alekseev BY, Kardymon OL, Sadritdinova AF, Fedorova MS, Pokrovsky AV, Melnikova NV, Kaprin AD et al. Mitochondrial dysfunction and oxidative stress in aging and cancer. Oncotarget. 2016;7(29):44879-905.

28. Snezhkina AV, Krasnov GS, Lipatova AV, Sadritdinova AF, Kardymon OL, Fedorova MS, Melnikova NV, Stepanov OA, Zaretsky AR, Kaprin AD, et al. The Dysregulation of Polyamine Metabolism in Colorectal Cancer is Associated with Overexpression of c-Myc and C/EBPbeta rather than Enterotoxigenic Bacteroides fragilis Infection. Oxidative Med Cell Longev. 2016;2016:2353560

29. Mundade R, Imperiale TF, Prabhu L, Loehrer PJ, Lu T. Genetic pathways, prevention, and treatment of sporadic colorectal cancer. Oncoscience. 2014;1(6):400-6.

30. Kong Y, Kumar SM, Xu X. Molecular pathogenesis of sporadic melanoma and melanoma-initiating cells. Arch Pathol Lab Med. 2010;134(12):1740-9.

31. Fedorova MS, Kudryavtseva AV, Lakunina VA, Snezhkina AV, Volchenko NN, Slavnova EN, Danilova TV, Sadritdinova AF, Melnikova NV, Belova $A A$, et al. Downregulation of OGDHL expression is associated with promoter hypermethylation in colorectal cancer. Mol Biol. 2015;49(4): 608-17.
32. Kudryavtseva AV, Lipatova AV, Zaretsky AR, Moskalev AA, Fedorova MS, Rasskazova AS, Shibukhova GA, Snezhkina AV, Kaprin AD, Alekseev BY, et al. Important molecular genetic markers of colorectal cancer. Oncotarget. 2016; 7(33):53959-83.

33. Burt RW, Bishop DT, Lynch HT, Rozen P, Winawer SJ. Risk and surveillance of individuals with heritable factors for colorectal cancer. WHO Collaborating Centre for the Prevention of Colorectal Cancer. Bull World Health Organ. 1990;68(5):655-65.

34. Taylor DP, Burt RW, Williams MS, Haug PJ, Cannon-Albright LA. Populationbased family history-specific risks for colorectal cancer: a constellation approach. Gastroenterology. 2010;138(3):877-85.

35. Debniak T. Familial malignant melanoma - overview. Hereditary Cancer Clin Pract. 2004;2(3):123-9.

36. Ni Y, Xie G, Jia W. Metabonomics of human colorectal cancer: new approaches for early diagnosis and biomarker discovery. J Proteome Res. 2014;13(9):3857-70.

37. Markovic SN, Erickson LA, Rao RD, Weenig RH, Pockaj BA, Bardia A, Vachon CM, Schild SE, McWilliams RR, Hand JL, et al. Malignant melanoma in the 21st century, part 1: epidemiology, risk factors, screening, prevention, and diagnosis. Mayo Clin Proc. 2007;82(3):364-80.

38. Siegel R, Naishadham D, Jemal A. Cancer statistics, 2013. CA Cancer J Clin. 2013;63(1):11-30.

39. Demierre MF. Epidemiology and prevention of cutaneous melanoma. Curr Treat Options in Oncol. 2006;7(3):181-6.

40. Siegel RL, Jemal A, Ward EM. Increase in incidence of colorectal cancer among young men and women in the United States. Cancer Epidemiol Biomarkers Prev. 2009;18(6):1695-8.

41. Bonuccelli G, Tsirigos A, Whitaker-Menezes D, Pavlides S, Pestell RG, Chiavarina B, Frank PG, Flomenberg N, Howell A, Martinez-Outschoorn UE, et al. Ketones and lactate "fuel" tumor growth and metastasis: Evidence that epithelial cancer cells use oxidative mitochondrial metabolism. Cell Cycle. 2010:9(17):3506-14.

42. Brizel DM, Schroeder T, Scher RL, Walenta S, Clough RW, Dewhirst MW, Mueller-Klieser W. Elevated tumor lactate concentrations predict for an increased risk of metastases in head-and-neck cancer. Int J Radiat Oncol Biol Phys. 2001;51(2):349-53.

43. Wyatt E, Wu R, Rabeh W, Park HW, Ghanefar M, Ardehali H. Regulation and cytoprotective role of hexokinase III. PLoS One. 2010;5(11):e13823.

44. Gottlob K, Majewski N, Kennedy S, Kandel E, Robey RB, Hay N. Inhibition of early apoptotic events by Akt/PKB is dependent on the first committed step of glycolysis and mitochondrial hexokinase. Genes Dev. 2001;15(11):1406-18.

45. Majewski N, Nogueira V, Bhaskar P, Coy PE, Skeen JE, Gottlob K, Chandel NS, Thompson CB, Robey RB, Hay N. Hexokinase-mitochondria interaction mediated by Akt is required to inhibit apoptosis in the presence or absence of Bax and Bak. Mol Cell. 2004;16(5):819-30.

46. Schindler A, Foley E. Hexokinase 1 blocks apoptotic signals at the mitochondria. Cell Signal. 2013;25(12):2685-92.

47. Pedersen PL. Voltage dependent anion channels (VDACs): a brief introduction with a focus on the outer mitochondrial compartment's roles together with hexokinase-2 in the "Warburg effect" in cancer. J Bioenerg Biomembr. 2008;40(3):123-6.

48. Chen J, Zhang S, Li Y, Tang Z, Kong W. Hexokinase 2 overexpression promotes the proliferation and survival of laryngeal squamous cell carcinoma. Tumour Biol. 2014:35(4):3743-53.

49. Anderson M, Marayati R, Moffitt R, Yeh JJ. Hexokinase 2 promotes tumor growth and metastasis by regulating lactate production in pancreatic cancer. Oncotarget, 2016. doi:10.18632/oncotarget.9760.

50. Suh DH, Kim MA, Kim H, Kim MK, Kim HS, Chung HH, Kim YB, Song YS. Association of overexpression of hexokinase II with chemoresistance in epithelial ovarian cancer. Clin Exp Med. 2014;14(3):345-53.

51. Massari F, Ciccarese C, Santoni M, lacovelli R, Mazzucchelli R, Piva F, Scarpelli M, Berardi R, Tortora G, Lopez-Beltran A, et al. Metabolic phenotype of bladder cancer. Cancer Treat Rev. 2016;45:46-57.

52. Kwee SA, Hernandez B, Chan O, Wong L. Choline kinase alpha and hexokinase-2 protein expression in hepatocellular carcinoma: association with survival. PLoS One. 2012;7(10):e46591.

53. Mathupala SP, Ko YH, Pedersen PL. Hexokinase II: cancer's double-edged sword acting as both facilitator and gatekeeper of malignancy when bound to mitochondria. Oncogene. 2006:25(34):4777-86. 
54. Patra KC, Wang Q, Bhaskar PT, Miller L, Wang Z, Wheaton W, Chandel N, Laakso M, Muller WJ, Allen EL, et al. Hexokinase 2 is required for tumor initiation and maintenance and its systemic deletion is therapeutic in mouse models of cancer. Cancer Cell. 2013;24(2):213-28.

55. Zhang Z, Huang S, Wang H, Wu J, Chen D, Peng B, Zhou Q. High expression of hexokinase domain containing 1 is associated with poor prognosis and aggressive phenotype in hepatocarcinoma. Biochem Biophys Res Commun. 2016;474(4):673-9.

56. Ogawa H, Nagano H, Konno M, Eguchi H, Koseki J, Kawamoto K, Nishida N, Colvin $H$, Tomokuni A, Tomimaru Y, et al. The combination of the expression of hexokinase 2 and pyruvate kinase $\mathrm{M} 2$ is a prognostic marker in patients with pancreatic cancer. Mol Clin Oncol. 2015;3(3):563-71.

57. Sato-Tadano A, Suzuki T, Amari M, Takagi K, Miki Y, Tamaki K, Watanabe M, Ishida T, Sasano H, Ohuchi N. Hexokinase II in breast carcinoma: a potent prognostic factor associated with hypoxia-inducible factor-1alpha and Ki-67. Cancer Sci. 2013;104(10):1380-8.

58. Palmieri D, Fitzgerald D, Shreeve SM, Hua E, Bronder $J$, Weil RJ, Davis S, Stark AM, Merino MJ, Kurek R, et al. Analyses of resected human brain metastases of breast cancer reveal the association between up-regulation of hexokinase 2 and poor prognosis. Mol Cancer Res. 2009;7(9):1438-45.

59. Bryson JM, Coy PE, Gottlob K, Hay N, Robey RB. Increased hexokinase activity, of either ectopic or endogenous origin, protects renal epithelial cells against acute oxidant-induced cell death. J Biol Chem. 2002;277(13): 11392-400.

60. Gao Y, Xu D, Yu G, Liang J. Overexpression of metabolic markers HK1 and PKM2 contributes to lymphatic metastasis and adverse prognosis in Chinese gastric cancer. Int J Clin Exp Pathol. 2015;8(8):9264-71.

61. He X, Lin X, Cai M, Zheng X, Lian L, Fan D, Wu X, Lan P, Wang J.

Overexpression of Hexokinase 1 as a poor prognosticator in human colorectal cancer. Tumour Biol. 2016;37(3):3887-95.

62. Hooft L, van der Veldt AA, van Diest PJ, Hoekstra OS, Berkhof J, Teule GJ. Molthoff CF: [18 F]fluorodeoxyglucose uptake in recurrent thyroid cancer is related to hexokinase i expression in the primary tumor. J Clin Endocrinol Metab. 2005;90(1):328-34.

\section{Submit your next manuscript to BioMed Central and we will help you at every step:}

- We accept pre-submission inquiries

- Our selector tool helps you to find the most relevant journal

- We provide round the clock customer support

- Convenient online submission

- Thorough peer review

- Inclusion in PubMed and all major indexing services

- Maximum visibility for your research

Submit your manuscript at www.biomedcentral.com/submit 